\title{
KOMPONEN EVALUASI LINGKUNGAN BELAJAR KLINIK, SUPERVISI DAN DOSEN PERAWAT
}

\author{
Fahruddin Kurdi ${ }^{1}$, Pepin Nahariani ${ }^{2}$, Ratna Puji Priyanti ${ }^{1}$ * \\ 1. Departemen KMB dan Kritis, STIKES Pemkab Jombang \\ 2. Departemen Keperawatan Dasar dan Manajemen Keperawatan, STIKES Pemkab \\ Jombang \\ *Email: ns.ratnapuji@gmail.com
}

\begin{abstract}
Abstrak:
Ners education in Indonesia is integrated between academic learning and clinical learning. The learning environment of conducive clinical practice is highly conquered. The environment in which, the atmosphere that supports students to learn. Things that are not obtained by nursing students in academic learning environment will be obtained at the time of clinical learning practice.

To identify students' perceptions of the clinical practice learning environment and supervision of the hospital-based clinical practice learning process in Indonesia and the influencing factors.

The design of this study used correlational analytic survey method with cross-sectional approach, with sampling technique of convinience sampling. The study population is Ners educational institution. The sample of research is 3 institution of Ners education organizer in East Java. Instruments using ELBKS + D Indonesian version.

Respondents aged between 20 to 28 years, 20-22 years of 89 (54.3\%), female sex of $115(70.1 \%)$. Medical Surgical Nursing became the most widely practiced stages of 62 $(37.8 \%)$. That the practical stages are significantly related to the role of the lecturer on the scale of ELBKS $+\mathrm{D}$ with $\mathrm{r}$-value $=0.158$ and $\rho$-value $=0.044$.

Discussion: Nursing students consider that the success of clinical teaching practice is determined primarily by the content of supervisory relationships and the role of nursing lecturers. The nurse lecturer role sub variable in ELBKS $+\mathrm{D}$ has correlation with student's precursor stages.
\end{abstract}

Keywords: Nursing Education, Clinical Learning Environment, Nursing Students, Role of Nurse Teacher

Abstrak: Pendidikan Ners di Indonesia terintegrasi antara pembelajaran akademik dan pembelajaran klinik. Lingkungan pembelajaran praktek klinik yang kondusif sangat diperlukkan. Lingkungan dimana, suasana yang mendukung mahasiswa untuk belajar. Hal-hal yang tidak didapatkan oleh mahasiswa keperawatan di lingkungan pembelajaran akademik, akan di dapatkan pada saat praktik pembelajaran klinik.

Mengidentifikasi persepsi mahasiswa dan faktor-faktor yang mempengaruhi mengenai lingkungan pembelajaran praktik klinik dan supervisi dari proses pembelajaran praktik klinik berbasis rumah sakit di Indonesia

Desain penelitian ini menggunakan metode survey analitik korelasional dengan pendekatan cross-sectional, dengan teknik sampling convinience sampling. Populasi penelitian adalah institusi penyelenggara pendidikan Ners. Sampel penelitian adalah 3 institusi penyelenggara pendidikan Ners di Jawa Timur. Instrumen menggunakan ELBKS + D versi Bahasa Indonesia.

Responden berusia antara 20 hingga 28 tahun, 20-22 tahun sebanyak 89 (54.3\%), jenis kelamin perempuan sebanyak 115 (70.1\%). Keperawatan Medikal bedah menjadi stase praktek terbanyak sebesar $62(37.8 \%)$. bahwa stase praktek secara signfikan 
berhubungan dengan peran dosen pada skala ELBKS + D dengan $r$-value $=0.158$ dan $\rho$ value $=0.044$.

Mahasiswa keperawatan mengatakan bahwa kesuksesan praktik pembelajaran klinik terutama ditentukan dari isi hubungan supervisi dan peran dosen perawat. Sub variabel peran dosen perawat dalam ELBKS+D memiliki korelasi dengan stase prakek mahasiswa.

Kata Kunci: Pendidikan Keperawatan, Lingkungan Pembelajaran Klinik, Mahasiswa Keperawatan, Peran Dosen Perawat

\section{PENDAHULUAN}

Mahasiswa keperawatan didorong untuk mempersiapkan diri sebelum diluluskan dan bekerja di praktik klinik. Hal-hal yang tidak didapatkan oleh mahasiswa keperawatan di lingkungan pembelajaran akademik, akan di dapatkan pada saat praktik pembelajaran klinik. Selama pembelajaran klinik mahasiswa keperawatan menjadi rentan, karena mahasiswa keperawatan pada masa ini di tuntut untuk belajar memberikan tindakan keperawatan secara langsung kepada pasien, sekaligus merasa peduli akan reaksi yang diberikan oleh staff keperawatan kepada usaha yang telah mereka lakukan (Chan, 2003). para peneliti memfokuskan pada apa yang dihadapi mahasiswa ketika berada di lingkungan praktek klinik, menggambarkan adanya kompleksitas dalam proses pembelajaran yang jauh dari prediksi dan kontrol pengajar akademik (Papp et al., 2003, Ip and Kit Chan, 2005, Chan, 2002, Chan, 2003).

\footnotetext{
Lingkungan pembelajaran praktek klinik yang kondusif sangat diperlukkan. Lingkungan dimana, suasana yang mendukung mahasiswa untuk belajar, mengenali kesalahan yang dilakukan, memberikan dukungan moril secara penuh, sebagai bagian dari proses pembelajaran (Warne et al., 2010). Demi terciptanya pembelajaran klinik yang efektif, kesenjangan antara pendidikan akademik dan praktik klinik harus selaras. Tuntutan hubungan yang selaras ini diinterprestasikan dalam
}

pengelolaan praktik pembelajran klinik sebagi dasar perencanaan dan evaluasi pengalaman belajar klinik (Chan, 2003). Namun, hubungan antara mahasiswa keperawatan dengan lingkungan klinik juga dinilai sangat penting demi membangun lingkungan belajar yang positif (Chan, 2003, Sellek, 1982).

Evaluasi tentang lingkungan pembelajaran praktik klinik berdasarkan persepsi mahasiswa keperawatan belum pernah di lakukan di Indonesia. Dengan adanya hasil penelitian ini, diharapkan sebagai dasar informasi untuk menciptakan suatu lingkungan pembelajaran yang lebih kondusif di praktik klinik. Sehingga, harapan untuk mempersiapkan mahasiswa sebagai perawat professional yang memiliki sikap, keahlian, dan nilai sebagai perawat professional dapat tercapai.

Tujuan penelitian ini adalah untuk mengidentifikasi persepsi mahasiswa mengenai lingkungan pembelajaran praktik klinik dan supervisi dari proses pembelajaran praktik klinik berbasis rumah sakit di Indonesia dan faktorfaktor yang mempengaruh.

\section{METODE}

Desain penelitian ini menggunakan metode survey analitik korelasional dengan pendekatan cross-sectional, dengan teknik sampling convinience sampling. Populasi penelitian adalah institusi penyelenggara pendidikan Ners. Sampel penelitian adalah 3 institusi penyelenggara pendidikan Ners di Jawa Timur. Ethical clearence 
Diperoleh dari komisi etik Fakultas Keperawatan Universitas Airlangga.

\section{Instrumen Penelitian}

Semua mahasiswa calon responden akan diberikan kuesioner khusus yang telah diterjemahkan kedalam Bahasa Indonesia. Kuesioner ini terdiri dari 2 bagian. Bagian pertama yaitu: data demografi meliputi umur, jenis kelamin, stase penempatan klinik. Bagian kedua adalah Clinical Learning Environment, Supervision and Nurse Teacher / CLES $+T$ Evaluation Scale (Skala Evaluasi Lingkungan Belajar Klinik, Supervisi dan Dosen Perawat) dibuat oleh Saarikoski dan Leino-Kili pada tahun 2008 (Saarikoski et al., 2008) berdasarkan teori mendasar pembelajaran klinik. Instrumen ini terdiri dari 34 pernyataan yang terbagi dalam 5 sub dimensi, yaitu: suasana strategi pembelajaran (pedagogi) di bangsal (9 pernyataan), hubungan supervisi (8 pernyataan), gaya kepemimpinan kepala ruangan /manajer bangsal (4 pernyataan), tempat pelayanan keperawatan (4 pernyataan), dan peran dosen perawat (9 pernyataan).

Versi bahasa Indonesia telah meliputi prosees validitas dan reliabilitas. Hasil S-CVI diperoleh 0.9405, sedangkan uji validitas menggunakan uji PCA dengan $\mathrm{N}=46$, diperoleh hasil eigenvalue dan explanation precentage sebesar $67 \%$, dan cronbach alpha sebesar 0.786 (Priyanti and Nahariani, 2016). Hasil ini serupa dengan hasil validitas dan reliabilitas pada pengembangan instrumen versi bahasa Inggris, PCA $67 \%$ dan cronbach alpha sebesar 0.90 (Saarikoski, 2002).

Analisa data menggunakan SPSS 17.00 for windows dengan uji deskriptif statistik dan uji bivariate dengan menggunakan uji pearson.

\section{HASIL\&PEMBAHASAN \\ Hasil \\ Data Demografi}

Total responden yang terkumpul dari 3 institusi adalah 180 responden. Dalam tahap tabulasi dan koding, 16 responden dihapus dikarenakan missing data. Sehingga, total responden tanpa missing data yang dianalisis secara satistik berjumlah 164 responden.

Dalam penelitian ini, karakteristik responden ditunjukkan dalam tabel 1 . Umur responden berkisar antara 20 hingga 28 tahun, dengan lebih dari setengah berumur 20-22 tahun sebanyak 89 responden $(54.3 \%)$. Sedangkan jenis kelamin sebagian besar perempuan sebanyak 115 responden (70.1\%). Keperawatan Medikal bedah menjadi stase praktek terbanyak sebesar 62 responden $(37.8 \%)$.

Tabel 1 Data Demografi

\begin{tabular}{|c|c|c|c|}
\hline Variabel & & $\begin{array}{c}\text { Frekuen } \\
\text { si (n) }\end{array}$ & $\begin{array}{c}\text { Presenta } \\
\text { se }(\%)\end{array}$ \\
\hline \multicolumn{4}{|l|}{ Umur } \\
\hline & $\begin{array}{l}20-22 \\
\text { tahun }\end{array}$ & 89 & 54.3 \\
\hline & $\begin{array}{l}23-35 \\
\text { tahun }\end{array}$ & 70 & 42.7 \\
\hline & $\begin{array}{l}26-28 \\
\text { tahun }\end{array}$ & 5 & 3.0 \\
\hline \multirow{2}{*}{\multicolumn{4}{|c|}{$\begin{array}{c}\text { Jenis } \\
\text { Kelamin }\end{array}$}} \\
\hline & & & \\
\hline & $\begin{array}{l}\text { Laki- } \\
\text { Laki }\end{array}$ & 49 & 29.9 \\
\hline & $\begin{array}{l}\text { Perem } \\
\text { puan }\end{array}$ & 115 & 70.1 \\
\hline \multirow{2}{*}{\multicolumn{4}{|c|}{$\begin{array}{c}\text { Stase } \\
\text { Praktek }\end{array}$}} \\
\hline & & & \\
\hline & $\begin{array}{l}\text { Kep. } \\
\text { Jiwa }\end{array}$ & 13 & 7.9 \\
\hline & Kep. & & \\
\hline & $\begin{array}{l}\text { Komu } \\
\text { nitas }\end{array}$ & 33 & 20.1 \\
\hline & $\begin{array}{l}\text { Kep. } \\
\text { Medik } \\
\text { al }\end{array}$ & 62 & 37.8 \\
\hline
\end{tabular}




\begin{tabular}{lll} 
Bedah & & \\
Kep. & 26 & 15.9 \\
Anak & & \\
Kep. & & \\
Mater & 15 & 9.1 \\
nitas & & \\
Kep. & & \\
Geront & 14 & 8.5 \\
ik & & \\
Kep. & 1 & 0.6 \\
Gadar & 1 & \\
\hline
\end{tabular}

Data Skala Evaluasi Lingkungan Belajar Klinik, Supervisi dan Dosen Perawat

Menggunakan versi bahasa Indonesia dalam mengevaluasi lingkungan belajar klinik, supervisi dan dosen perawat, responden diminta untuk menilai lingkungan belajar kelinik di rumah sakit. Dengan menggunakan skala likert (1-sangat tidak setuju, 2sangat seuju, 3-netral, 4-setuju, 5-sangat setuju. Menggunakan uji univariat menggunakan SPSS for windows untuk mengetahui sebaran data deskriptif. Pada tabel 2, masing-masing subdimensi dari Skala ELBKS+D nilai Mean berkisar 3.64 hingga 3.83. Nilai isi hubungan supervisi mmperoleh nilai tertinggi dengan $M=3.83$; SD: 0.426 .

Responden diminta untukk mendeskripsikan jenis supervisi yang diterima selama melakukan prakek klinik di Rumah Sakit seperti tercantum dalam tabel 3. Lebih dari setengah, mahasiswa disupervisi oleh manajer bangsal, sebagai suppervisor sebanyak 92 responden (56.1\%). Dan sebanyak 61 responden $(37.2 \%)$, mendapatkan 1 supervisor yang sama untuk 1 kelompok. Terjadinya supervisi, dikatakan oleh 56 responden $(34.1 \%)$, terjadi 1 kali dalam seminggu.

Tabel 2 Skala Evaluasi Lingkungan Belajar Klinik, Supervisi dan Dosen Perawat N=164

\begin{tabular}{llll} 
Sub Dimensi & M & S & SE \\
\hline
\end{tabular}

\begin{tabular}{lccc}
\hline & \multicolumn{3}{c}{$\mathrm{D}$} \\
\hline & 3. & & \\
Atmosfer Pedagogi di & 6 & 0.4 & 0.0 \\
Bangsal/Ruangan & 4 & 61 & 36 \\
& 3. & & \\
Gaya Kepemimpinan & 7 & 0.5 & 0.0 \\
Manajer Bangsal & 6 & 39 & 42 \\
& 3. & & \\
Premises Pelayanan & 6 & 0.4 & 0.0 \\
Keperawatan di Bangsal & 5 & 76 & 37 \\
& 3. & & \\
& 8 & 0.4 & 0.0 \\
Isi Hubungan Supervisi & 3 & 26 & 33 \\
& 3. & & \\
& 8 & 0.4 & 0.0 \\
Peran Dosen Perawat & 2 & 96 & 39 \\
\hline
\end{tabular}

\begin{tabular}{lcc} 
Tabel 3 Supervisi & \multicolumn{2}{c}{$\mathrm{N}=164$} \\
\hline \multirow{2}{*}{ Varia } & Frekue & Present \\
bel & nsi & ase \\
& (n) & $(\%)$ \\
\hline
\end{tabular}

Jabatan kerja

Supervisor

$\begin{array}{lcc}\text { Perawat } & 33 & 20.1 \\ \text { Perawat } & 5 & 3.0 \\ \begin{array}{l}\text { Spesialis } \\ \text { Asisten } \\ \text { manajer } \\ \text { bangsal/rua } \\ \text { ngan }\end{array} & 34 & 20.7 \\ \begin{array}{l}\text { Manajer } \\ \text { bangsal/rua } \\ \text { ngan }\end{array} & 92 & 56.1 \\ \text { gra } & & \end{array}$

Supervisor

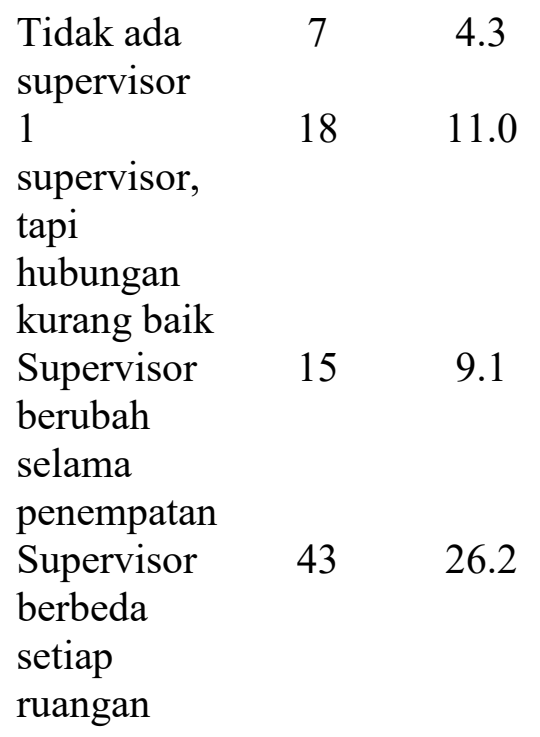




$\begin{array}{lll}\begin{array}{l}\text { Supervisor } \\ \text { sama untuk }\end{array} & 61 & 37.2 \\ 1 \text { kelompok } & & \\ 1 & 20 & 12.2 \\ \text { supervisor } & & \\ \text { dan } & & \\ \text { hubungan } & & \\ \text { baik } & & \end{array}$

Terjadinya supervisi

\begin{tabular}{lcc}
$\begin{array}{l}\text { Tidak sama } \\
\text { sekali }\end{array}$ & 39 & 23.8 \\
$\begin{array}{l}1 \text { atau 2 } \\
\text { kali selama } \\
\text { program }\end{array}$ & 39 & 23.8 \\
$\begin{array}{l}\text { Kurang dari } \\
1 \text { kali }\end{array}$ & 20 & 12.2 \\
$\begin{array}{l}\text { seminggu } \\
1 \text { kali }\end{array}$ & 56 & 34.1 \\
$\begin{array}{l}\text { seminggu } \\
\text { Sering }\end{array}$ & 10 & 6.1 \\
\hline
\end{tabular}

Hasil uji bivariate data demografi dengan skala ELBKS + D menunjukkan bahwa stase praktek secara signfikan berhubungan dengan peran dosen pada skala ELBKS+D dengan $r$-value $=0.158$ dan $\rho$-value $=$ 0.044. sedangkan data demografi meliputi umur, jenis kelamin dan stase praktek tidak memiliki hubungan secara signifikan dengan skala ELBKS+D. (Lihat tabel 4)

Berdasarkan hasil analisa univariate, sub-dimensi isi hubungan supervisi mendapatkan nilai Mean tertinggi. Ditunjukkan dengan nilai $\mathrm{M}=$ 3.83, $\mathrm{SD}=0.426$. Sedangkan untuk sub-dimensi terjadinya supervisi, 92 responden $(56.1 \%)$ disupervisi oleh manajer bangsal atau biasa disebut kepala ruangan, 61 responden $(37.2 \%)$ mendapatkan satu orang supervisor untuk satu kelompok, dan 56 responden (34.1\%) mendapatkan supervisi satu kali seminggu.

Tabel 4: Uji Bivariate skala ELBKS+D dengan data demografi

$$
\mathrm{N}=164
$$

\begin{tabular}{|c|c|c|c|c|}
\hline & & $\begin{array}{c}\mathrm{U} \\
\mathrm{mu} \\
\mathrm{r}\end{array}$ & JK & $\begin{array}{l}\text { StaseP } \\
\text { raktek }\end{array}$ \\
\hline Atmosfer & Pears & - & - & 0.091 \\
\hline Pedagogi & on & 0.0 & 0.0 & \\
\hline $\begin{array}{l}\text { di } \\
\text { Bangsal/ }\end{array}$ & $\begin{array}{l}\text { Correl } \\
\text { ation }\end{array}$ & 08 & 83 & \\
\hline Ruangan & $\begin{array}{l}\text { Sig. } \\
(2- \\
\text { tailed })\end{array}$ & $\begin{array}{r}0.9 \\
20\end{array}$ & $\begin{array}{r}0.2 \\
93\end{array}$ & 0.245 \\
\hline $\begin{array}{l}\text { Gaya } \\
\text { Kepemim } \\
\text { pinan } \\
\text { Manajer }\end{array}$ & $\begin{array}{l}\text { Pears } \\
\text { on } \\
\text { Correl } \\
\text { ation }\end{array}$ & $\begin{array}{r}- \\
0.0 \\
68\end{array}$ & $\begin{array}{r}0.0 \\
53\end{array}$ & -0.073 \\
\hline Bangsal & $\begin{array}{l}\text { Sig. } \\
(2- \\
\text { tailed })\end{array}$ & $\begin{array}{r}0.3 \\
84\end{array}$ & $\begin{array}{r}0.5 \\
03\end{array}$ & 0.354 \\
\hline Premises & Pears & - & - & 0.098 \\
\hline Pelayana & on & 0.0 & 0.0 & \\
\hline $\begin{array}{l}\mathrm{n} \\
\text { Keperaw }\end{array}$ & $\begin{array}{l}\text { Correl } \\
\text { ation }\end{array}$ & 39 & 43 & \\
\hline atan di & Sig. & 0.6 & 0.5 & 0.214 \\
\hline Bangsal & $\begin{array}{l}(2- \\
\text { tailed) }\end{array}$ & 19 & 85 & \\
\hline Isi & Pears & - & - & 0.132 \\
\hline Hubunga & on & 0.0 & 0.1 & \\
\hline $\begin{array}{l}\mathrm{n} \\
\text { Supervisi }\end{array}$ & $\begin{array}{l}\text { Correl } \\
\text { ation }\end{array}$ & 54 & 89 & \\
\hline & $\begin{array}{l}\text { Sig. } \\
(2- \\
\text { tailed) }\end{array}$ & $\begin{array}{r}0.4 \\
96\end{array}$ & $\begin{array}{r}0.0 \\
16\end{array}$ & 0.092 \\
\hline Peran & Pears & - & - & 0.158 \\
\hline Dosen & on & 0.0 & 0.0 & \\
\hline Perawat & $\begin{array}{l}\text { Correl } \\
\text { ation }\end{array}$ & 73 & 58 & \\
\hline & $\begin{array}{l}\text { Sig. } \\
(2- \\
\text { tailed })\end{array}$ & $\begin{array}{r}0.3 \\
52\end{array}$ & $\begin{array}{r}0.4 \\
61\end{array}$ & $0.044 *$ \\
\hline TOTAL & $\begin{array}{l}\text { Pears } \\
\text { on } \\
\text { Correl } \\
\text { ation }\end{array}$ & $\begin{array}{r}- \\
0.0 \\
62\end{array}$ & $\begin{array}{r}- \\
0.0 \\
74\end{array}$ & 0.097 \\
\hline & $\begin{array}{l}\text { Sig. } \\
(2- \\
\text { tailed })\end{array}$ & $\begin{array}{r}0.4 \\
27\end{array}$ & $\begin{array}{r}0.3 \\
49\end{array}$ & 0.217 \\
\hline
\end{tabular}

Pada hasil analisa bivariate, hasil uji korelasi Pearson antara sub 
variabel ELBKS $+\mathrm{D}$ dengan data demografi diperoleh $\mathrm{P}$-value $>0.05$. Hal ini bearti tidak ada hubungan yang signifikan anara sub variabel ELBKS + D dengan data demografi. Tetapi, hasil uji Pearson antara peran dosen perawat dengan stase praktek memperoleh nilai p-value $0.044<\alpha$ 0.05 , sehingga ada hubungan yang signifikan dengan $\mathrm{r}$-value $=0.158$.

b. Pembahasan

\section{Skala Evaluasi Lingkungan Belajar} Klinik, Supervisi dan Dosen Perawat Kurikulum pendidikan keperawatan di Indonesia selain pendidikan akademik, diperlukan pembelajaran klinik untuk meningkatkan kompetensi lulusan. Pembelajaran klinik, bertujuan untuk membekali mahasiswa suatu kompetensi klinik, dengan pendekatan langsung kepada pasien unuk meningkatkan kompetensi profesional (Chan, 2002, Chan, 2003, Wong and Wong, 1987). Dalam pembelajaran klinik yang kompleks dan tidak terduga, mahasiswa menjadi rentan stress sehingga mempengaruhi proses belajar (Ip and Kit Chan, 2005, Papp et al., 2003, Elliott, 2002). Tidak hanya itu, hubungan supervisi, budaya, struktur organisasi, dan atmosfir ruangan mempengaruhi lingkungan belajar klinik (Saarikoski, 2002). Menurut, peneliti terdahulu, kualitas pelayanan memberikan peranan yang besar dalam lingkungan pembelajaran klink mahasiswa (Papastavrou et al., 2010, Warne et al., 2010), dan staf keperawatan sebagai role model dalam memberikan pelayanan profesional keada pasien (Papp et al., 2003). Model preceptorship menurut peneliti terdahulu dianggap paling sesuai dalam praktik pembelajaran klinik (Elliott, 2002, Pierce, 1991, Dilbert and Goldenberg, 1995, Clayton et al., 1989).
Menurut hasil penelitian, mahasiswa menganggap peran dosen keperawatan sangat penting bagi mahasiswa dalam pencapaian proses pembelajaran klinik. Hal ini tidak sesuai dengan penelitian terdahulu dimana staf perawat dan kualitas pelayanan keperawatan diruangan menjadi hal yang utama. Demikian juga dengan pola supervisi, terbatasnya jumlah preceptor diklinik, mengakibatkan suupervisor yang bertugas dalam praktik pembelajaran klinik hanya satu orang untuk satu kelompok. Terlebih lagi, tingginya beban kerja perawat pelaksana, maka sebagian besar perawat yang bertugas sebagai supervisor adalah manajer bangsal atau kepala ruangan.

\section{SIMPULAN}

Mahasiswa

keperawatan menganggap bahwa kesuksesan praktik pembelajaran klinik terutama ditentukan dari isi hubungan supervisi dan peran dosen perawat. Sub variabel peran dosen perawat dalam ELBKS + D memiliki korelasi dengan stase prakek mahasiswa.

Penelitian ini menunjukkan bahwa terjadinya lingkungan pembelajaran yang efektif ditentukan oleh beberapa faktor. Menurut persepsi mahasiswa, faktor isi hubungan supervisi, atmosfer pedagogi di bangsal/ruangan dan peran dosen perawat memberikan kontribusi yang besar dalam menciptakan lingkungan belajar klinik yang kondusif.

\section{Daftar Pustaka}

CHAN, D. S. K. 2002. Associations between student learning outcomes from their clinical placement and their perceptions of the social climate of the clinical learning environment. International Journal o Nursing Studies, 39, 517-524.

CHAN, D. S. K. 2003. Validation of the Clinical Learning Environment 
Inventory. Western Journal of

Nursing Research, 25, 519-532.

CLAYTON, G., BROOME, M. \&

ELLIS, L. 1989. Relationship

between a preceptorship

experience and role socialization

of graduate nurses. Journal of

Nursing Education, 28, 72-75.

DILBERT, C. \& GOLDENBERG, D. 1995. Preceptors' perceptions of benefits, rewards, supports and commitment to preceptor role. Journal of Advanced Nursing, 21, 1144-1151.

ELLIOTT, M. 2002. The Clinical environment: A source of stress for undergraduate nurses. Australian Journal of Advanced Nursing, 20, 34-38.

IP, W. Y. \& KIT CHAN, D. S. 2005. Hong Kong nursing students' perception of the clinical environment: a questionnaire survey. Int J Nurs Stud, 42, 665 672.

PAPASTAVROU, E., LAMBRINOU, E., TSANGARI, H., SAARIKOSKI, M. \& LEINOKILPI, H. 2010. Student nurses experience of learning in the clinical environment. Nurse Education in Practice, 10, 17682.

PAPP, I., MARKKANEN, M. \& VON BONSDORFF, M. 2003.

Clinical environment as a learning environment: student nurses' perceptions concerning clinical learning experiences. Nurse Education Today, 23, 262-268.

PIERCE, A. 1991. Preceporial students' view of their clinical experience. Journal of Nursing Education, 30, 244-250.
PRIYANTI, R. P. \& NAHARIANI, P. 2016. Skala evaluasi lingkungan belajar klinik, supervisi dan dosen perawat (Clinical learning environment, supervission and nurse teacher - CLES $+T$ ) versi bahasa Indonesia: Validitas dan reliabilitas. Jurnal Ilmiah Kesehatan, 9, 107-113.

SAARIKOSKI, M. 2002. Clinical Learning environment and supervision: Development and validation of the CLES evaluation sclae. Doctorate, Turku University.

SAARIKOSKI, M., ISOAHO, H., WARNE, T. \& LEINO-KILPI, H. 2008. The nurse teacher in clinical practice: Developing the new sub-dimension to the clinical learning environment and supervision (CLES) scale. International Journal of Nursing Studies, 45, 1233-1237.

SELLEK, T. 1982. Satisfying and anxiety-creating incidents for nursing students. Nursing Times, 78, 137-140.

WARNE, T., JOHANSSON, U. B., PAPASTAVROU, E., TICHELAAR, E., TOMIETTO, M., VAN DEN BOSSCHE, K., MORENO, M. F. \& SAARIKOSKI, M. 2010. An exploration of the clinical learning experience of nursing students in nine European countries. Nurse Educaton Today, 30, 809-15.

WONG, J. \& WONG, S. 1987. Towards effective clinical teaching in nursing. Journal of Advanced Nursing, 12, 505-513. 